\title{
Adjuvant Role of Botulinum Toxin A in the Management of Wounds Accompanied by Parotid Gland or Duct Injuries
}

\author{
Yeonjin Jeong ${ }^{1}$ (D), Sang-Yeul Lee ${ }^{1}$ (D), Kun-Yong Sung ${ }^{2}$ (C) \\ ${ }^{1}$ Department of Plastic and Reconstructive Surgery, Kangwon National University Hospital, Chuncheon; ${ }^{2}$ Department of Plastic and Reconstructive Surgery, \\ Kangwon National University School of Medicine, Chuncheon, Korea
}

\begin{abstract}
Background: Parotid gland or duct injuries may occur after facial trauma or surgical procedures around the parotid gland. Such injuries often cause saliva to leak into the wound, and as a result, the autolytic enzymes in the saliva can delay wound healing. To promote wound healing in such cases, salivary leakage must be stopped until the wound has completely healed. Though there are several known measures for preventing salivary leakage, including compressive dressings, suction drainage, food restriction, and anticholinergic drugs, they often yield unsatisfactory results. This study aimed to evaluate the clinical efficacy of botulinum toxin A in stopping salivary secretions and inducing wound healing in wounds accompanied by parotid gland or duct injuries.

Methods: A retrospective study was conducted to evaluate the efficacy of botulinum toxin A for treating salivary leakage due to parotid gland or duct injuries. Five patients were treated between 2011 and 2016, three of whom received postoperative injections with a total dose of 30-40 units of botulinum toxin A. One of the other two patients was injected with the same amount of botulinum toxin A preoperatively, and the other received an intraoperative injection.

Results: All five patients showed an abrupt decrease of salivary leakage on the 3rd day after toxin injection and satisfactory wound healing without untoward side effects.

Conclusion: This study demonstrates the critical role played by botulinum toxin A in management of wounds complicated by abnormal leakage of saliva, when the parotid gland or duct is injured.
\end{abstract}

Keywords: Salivary glands; Salivary ducts; Botulinum toxins; Saliva; Facial injuries

\section{Introduction}

The parotid gland or duct can be injured due to deep lacerations of the cheek or surgical procedures such as parotidectomy, rhytidectomy, mastoidectomy, and skin tumor resection. These injuries cause abnormal leakage of saliva into the wound, and autolytic enzymes in salivary secretions can critically impair wound healing. Therefore, these injuries should be detected early and repaired properly to return parotid function to normal [1]. However, early diagnosis and appropriate management are often delayed or missed, which may result in serious complications such as sialocele or parotid fistula. Even if such injuries are found early and repaired adequately, salivary leakage can develop as a complication. Salivary leakage is very distressing, both to the patient and to the surgeon, because conservative and surgical treatments are often unsatisfactory. In order to heal wounds complicated by the leakage of saliva caused by parotid injury, it is necessary to reduce or stop salivary secretions for an adequate period. Before the introduction of botulinum toxin for clinical use, various treatment

\section{Original Article}

Received: November 30, 2020

Revised: January 27, 2021

Accepted: January 29, 2021

\section{Corresponding author: Kun-Yong Sung, M.D., Ph.D.}

Department of Plastic and Reconstructive Surgery, Kangwon National University School of Medicine, 1 Gangwondaehak-gil, Chuncheon 24341, Korea

Tel: +82-33-258-9206

Fax: +82-33-258-4920

E-mail: ps@kangwon.ac.kr

This is an Open Access article distributed under the terms of the Creative Commons Attribution Non-Commercial License (https://creativecommons.org/licenses/by-nc/4.O/) which permits unrestricted non-commercial use, distribution, and reproduction in any medium, provided the original work is properly cited.

C 2021 Korean Wound Management Society 
modalities had been used for this purpose, including restriction of oral intake, anticholinergic drugs, tympanic neurectomy, radiation, and parotidectomy, with varying results [2-7]. Meanwhile, over the last two decades, researchers have advocated injecting botulinum toxin type A into the parotid gland as an alternative treatment option to decrease salivary secretions, and multiple reports have confirmed that botulinum toxin A is effective for treating parotid fistula or sialocele [814]. Herein, we present five cases involving parotid gland or duct injuries that were successfully treated with botulinum toxin A injection (Table 1).

\section{Methods}

A retrospective study was conducted to evaluate the efficacy of botulinum toxin A for treating salivary leakage from parotid gland or duct injuries. Five patients were treated between 2011 and 2016, three of whom received postoperative injections with a total dose of 30-40 units of botulinum toxin A (Botox, Allergan, Irvine, CA, USA) after reconstituting a 100-unit vial with $3 \mathrm{~mL}$ of normal saline. One of the other two patients was injected with the same amount of botulinum toxin A preoperatively, and the other received an intraoperative injection. The toxin was injected into four to eight sites of the parotid gland with a divided dose using an insulin syringe or a $1 \mathrm{~mL}$ syringe with a 30-gauge needle, and in one patient, the injections were made under ultrasonographic guidance. In the other four patients, the toxin was injected without the aid of imaging tools. This study was approved by the Institutional Review Board (IRB) of Kangwon National University Hospital (IRB No. KNUH-2020-12-003). The patients provided written informed consent for the publication and the use of their images.

\section{Results}

All five patients showed an abrupt decrease of salivary leakage on the 3rd day after the toxin injection and exhibited satisfac- tory wound healing without untoward side effects. No recurrence was observed in any of the five patients during follow-up periods ranging from 3 to 20 months.

\section{Case presentations}

Case 1

A 72-year-old woman presented with watery, clear discharge from a very small opening on her left cheek. The discharge had lasted for 6 months and increased during food intake. Her medical history revealed acute suppurative parotitis 6 months earlier. At that time, she was treated with incision and drainage, followed by antimicrobial medication. On physical examination, there was a $2 \mathrm{~mm}$-diameter opening with surrounding scar tissue on the left cheek (Fig. 1A). Laboratory analysis of the fluid revealed an elevated amylase level (more than 300,000 $\mathrm{IU} / \mathrm{mL}$ ), which confirmed saliva leakage from a parotid fistula. The left parotid gland was demarcated by a radiologist with an ultrasound scan, and 40 units of Botox were injected preoperatively into four separate subdivisions of the left parotid gland in divided doses. On day 3 after the injection, the discharge from the left cheek began to decrease and ceased completely on day 5. On day 7 after botulinum toxin injection, fistulectomy was performed under local anesthesia. The wound healed well without any complication. The postoperative course was uneventful at the 13-month follow-up (Fig. 1B).

\section{Case 2}

A 47-year-old man was injured on his left cheek by glass. On his visit to emergency room, only skin laceration was repaired after insertion of a silastic drain (Fig. 2A). In response to gustatory stimuli after skin repair, profuse clear fluid discharged out of the drain site. Under the impression of a parotid duct injury, his cheek was explored on the next day and the severed parotid duct was repaired after inserting a silastic stent. However, leakage of saliva developed on the next day, and did not stop despite conservative management including restriction of oral food intake and compression. On postoperative day 7, 40

Table 1. Clinical analysis of patients

\begin{tabular}{|c|c|c|c|c|c|}
\hline Case No. & Age (yr) & Sex & Cause of salivary leakage & Botulinum toxin dose used (unit) & Timing of injection \\
\hline 1 & 72 & Female & Suppurative parotitis & 40 & Preoperative \\
\hline 2 & 47 & Male & Facial injury & 40 & Postoperative \\
\hline 3 & 48 & Male & Facial injury & 40 & Postoperative \\
\hline 4 & 76 & Female & latrogenic & 30 & Intraoperative \\
\hline 5 & 71 & Female & latrogenic & 40 & Postoperative \\
\hline
\end{tabular}



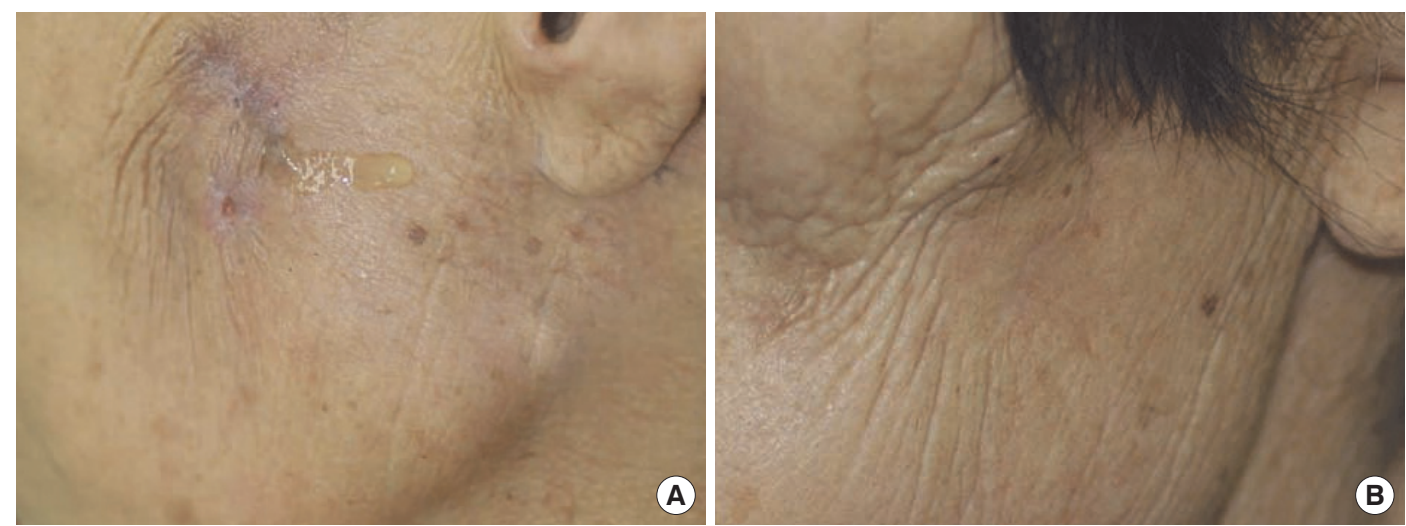

Fig. 1. Treatment of case 1. (A) Preoperative view of a parotid fistula with salivary discharge. The left parotid gland was demarcated preoperatively with an ultrasound scan. The red dots depict markings for botulinum toxin injection. (B) Postoperative 13-month view showing complete healing of the parotid fistula.
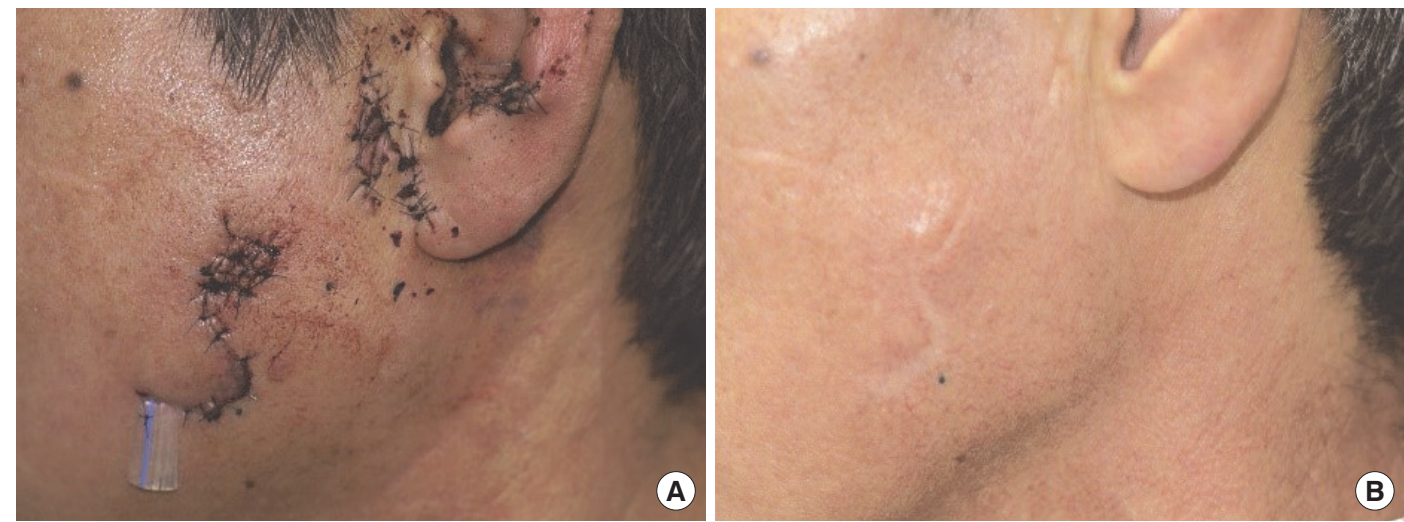

Fig. 2. Treatment of case 2. (A) Postoperative view showing saliva secretion through the drain site after repair of the severed parotid duct. (B) Postoperative 20-month view showing complete healing.

units of Botox were injected into five sites in the left parotid gland in divided doses. The leakage stopped 5 days after the botulinum toxin A injection. The silastic stent was kept for 3 weeks. The patient has remained well during 20 months of follow-up (Fig. 2B).

\section{Case 3}

A 48-year-old man was injured deeply on his right cheek by a sharp metal object. An emergency operation was performed to explore and repair the wound. Injuries of the parotid gland parenchyma and the facial nerve (buccal and zygomatic branch) were repaired with caution. Oral food intake was not allowed for 5 days after the operation. On starting oral intake on postoperative day 6, his cheek became swollen (Fig. 3A). Under the impression of salivary leakage into the wound, a total of 40 units of Botox were injected at eight sites of the right parotid gland in divided doses. On day 3 after toxin injection, leakage of saliva began to decrease gradually. The wound healed well eventually. No recurrence was found at the 3-month follow-up (Fig. 3B).

\section{Case 4}

A 76-year-old woman underwent surgical excision for a squamous cell carcinoma on her right cheek. During the operation, a small part of the parotid duct was resected because of tumor invasion, during which the parotid capsule was injured inadvertently. After repair of the parotid capsule and ligation of the proximal Stensen duct, 30 units of Botox were injected at six sites on the right parotid gland intraoperatively. The open wound after tumor resection was repaired with a rotational skin flap from the neck. For 3 days after the operation, clear fluid collected in the suction drainage bottle despite food restrictions, and the fluid was revealed to be saliva in an amylase test. On postoperative day 4 , there was only minimal fluid col- 

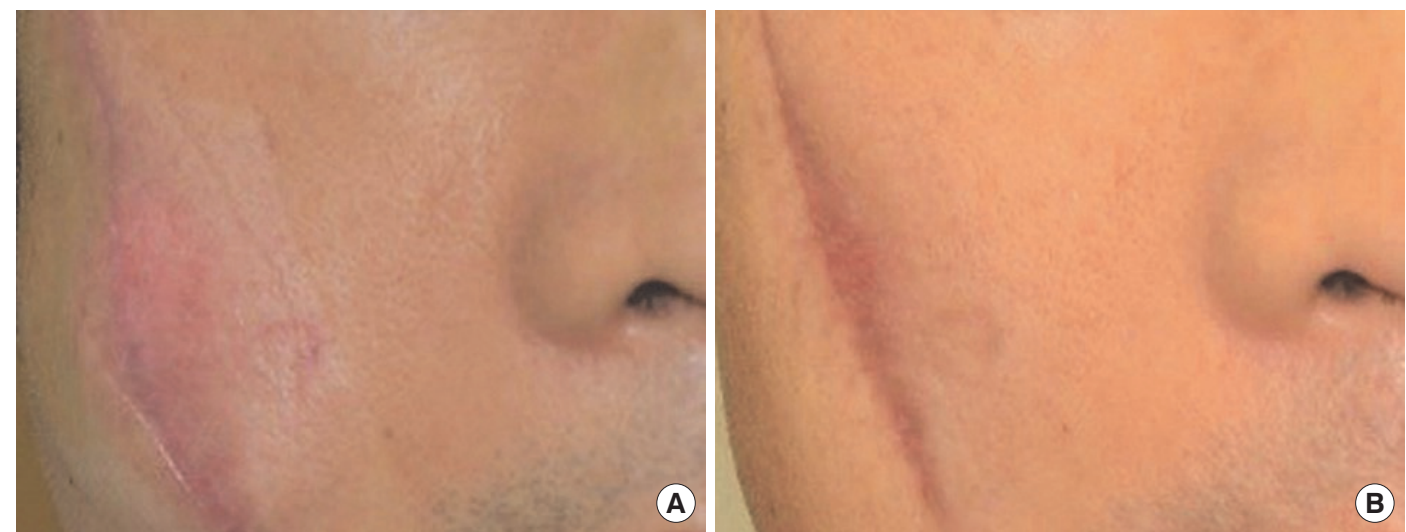

Fig. 3. Treatment of case 3. (A) Postoperative view showing cheek swelling after repair of a parenchymal injury of the right parotid gland and facial nerve branches. (B) Postoperative 3-month view showing complete healing (right).

lection. The wound healed completely by 2 weeks after surgery. No salivary disorders such as fistula or sialocele were observed at a 6-month follow-up.

\section{Case 5}

A 71-year-old woman underwent surgical excision for a Merkel cell tumor on her left cheek. During resection of the tumor, the parotid capsule was injured. After repairing the capsule, the surgical wound was covered with a rotational skin flap from the neck. Until the 2nd day after the operation, clear fluid discharged at the drain site, and the fluid was confirmed to be saliva in an amylase test. On postoperative day 3, 40 units of Botox were injected at eight sites into the right parotid gland in divided doses. On the 3rd day after the toxin injection, the clear discharge began to decrease and stopped on day 5 . The surgical wound healed uneventfully. The patient has remained well during 3 months of follow-up.

\section{Discussion}

Physicians often encounter surgical wounds complicated by abnormal leakage of saliva, which is caused by parotid or duct injuries. In order to achieve desirable results from wound treatment, salivary secretion must be reduced or ceased because the autolytic enzymes in saliva hinder wound healing and cause infection. In the past, several conservative methods such as compressive dressings, suction drainage, food restriction, and anticholinergic drugs have been tried to reduce salivary secretions and promote healing. However, their effects were often disappointing. Prior to introduction of Botox toxin injections for treatment of parotid fistulas, only $50 \%$ of patients with longstanding parotid fistulas found success with conventional treatments [7].

Anticholinergic drugs reduce salivary secretions temporarily, but their use has been limited due to their profile of side effects, including palpitation, tachycardia, photophobia, urine retention, blurred vision, and dryness of mouth. In contrast, botulinum toxin only acts on the injected parotid gland and reduces salivary secretions without systemic side effects. Although some surgeons recommend the concomitant use of botulinum toxin with antisialogogue drugs such as scopolamine $[15,16]$ and atropine [17], this is not necessary because the botulinum toxin injection is sufficiently effective on its own to inhibit salivary secretion. Botulinum toxin injection was first proposed in 1997 by Bushara [18] as an alternative approach to manage secretory disorders of the parotid glands. Bushara reported favorable results of botulinum toxin A injection in treating sialorrhea in patients who had amyotrophic lateral sclerosis or other neurological disorders. It has long been known that botulinum toxin A blocks neuromuscular junction and all autonomic cholinergic fibers, including major secretomotor parasympathetic fibers, to the salivary glands. Although botulinum toxin A injection has been frequently used to treat spasmodic torticollis, hemifacial spasm, blepharospasm, and expressional wrinkles for cosmetic use, it has also been applied to treat parotid fistula, sialocele, recurrent parotitis and salivary secretory disorders such as neurologic sialorrhea and Frey syndrome [8-14,18-20].

Parotid fistulas are more frequently associated with gland injuries than with duct injuries. Parotid duct injuries are often overlooked in trauma cases, or are irreparable in cases of severe injuries even if they are recognized. Missed or irreparable parotid duct injuries may eventually result in parotid fistulas, which can be effectively managed using botulinum toxin A. 
Our study also included a case of parotid fistula caused by duct injury. In acute parotid fistula, the toxin is usually injected postoperatively. However, a preoperative injection is needed to prevent postoperative salivary secretions in chronic fistula cases. An intraoperative injection can also be performed to prevent parotid fistula when an iatrogenic gland injury occurs during surgery.

Some researchers injected the toxin into the parotid parenchyma under ultrasonographic assistance [11,12], and others did so under electromyographic control $[10,19]$. Although it is not mandatory, preoperative demarcation the parotid gland with an ultrasound scan is very helpful for injecting the toxin into the parotid parenchyma and avoiding untoward side effects. The toxin was injected in our patients using an insulin syringe or a $1 \mathrm{~mL}$ syringe with a 30-gauge needle, depending on the thickness of skin and subcutaneous tissue. The appropriate doses and injection techniques to obtain optimal results remain controversial. Capaccio et al. [11] suggested that each parotid gland should receive 25-60 units of botulinum neurotoxin type A (Botox, Allergan), and proposed that the treatment should be fractionated into four doses (for the lower, upper, posterior, and anterior quadrants), none of which should contain more than 15 units. Arnaud et al. [20] used 100 units of Botox, and von Lindern et al. [9] used 450 units of Dysport (Ipsen Pharma) for parotid fistula treatment, corresponding in clinical efficacy to about 150 units of Botox. Jung et al. [15] injected a total of 50 units of botulinum toxin type A (Botulax; Hugel, Inc.) in all injection sites, which were $1 \mathrm{~cm}$ apart, with successful results in treating parotid fistula complicated by face lift surgery. In our studies, a total dose of 30-40 units of Botox was used to stop salivary secretion through injections at four to eight sites in divided doses. We injected relatively low doses of toxin compared to the doses used by other researchers, which may inform future research investigating the minimum effective dose to stop salivary secretions. In our study, 30 units of Botox was the minimum dose. However, further investigation should be carried out to determine the adequate dose and proper distances between injection sites to obtain optimal results for managing wounds complicated by salivary leakage. Most of our patients showed an abrupt decrease of salivary secretions on the 3rd day after the toxin injection, and secretions almost stopped around the 5th day.

No postoperative complications were observed in any of the five patients, including the patient with the longest follow-up period of 20 months. Considering that the effect of botulinum toxin A usually lasts from 3 to 6 months, the absence of recur- rence in our three patients who were followed up for more than 6 months suggests that repeated toxin injections are not necessary. Instead, a single injection can inhibit salivary secretions for a duration long enough for the wound to heal.

In conclusion, the injection of botulinum toxin type A with a dose equivalent to $30-40$ units of Botox is suggested as a safe, effective, and reasonable therapy to manage wounds complicated by parotid gland or duct injuries.

\section{Conflict of interest}

Kun-Yong Sung is an editorial board member of the journal but was not involved in the peer reviewer selection, evaluation, or decision process of this article. No other potential conflicts of interest relevant to this article were reported.

\section{ORCID iDs}

Yeonjin Jeong

Sang-Yeul Lee

Kun-Yong Sung

https://orcid.org/0000-0003-0062-8546

https://orcid.org/0000-0001-5262-1499

https://orcid.org/0000-0002-3114-0001

\section{References}

1. Parekh D, Glezerson G, Stewart M, et al. Post-traumatic parotid fistulae and sialoceles: a prospective study of conservative management in 51 cases. Ann Surg 1989;209:10511.

2. Lichtenstein JL, Kopp WK. Closure of a parotid salivary fistula. J Oral Surg 1965;23:497-8.

3. Schindel J, Markowicz H, Levie B. Combined surgical-radiological treatment of parotid gland fistulae. J Laryngol Otol 1968;82:867-70.

4. Baron HC. Surgical correction of salivary fistula: report of five cases. Ann Surg 1961;153:545-54.

5. Arulpragasam AC. On the treatment of parotid fistulae. J Laryngol Otol 1967;81:329-37.

6. Davis WE, Holt GR, Templer JW. Parotid fistula and tympanic neurectomy. Am J Surg 1977;133:587-9.

7. Ananthakrishnan N, Parkash S. Parotid fistulas: a review. Br J Surg 1982;69:641-3.

8. Vargas H, Galati LT, Parnes SM. A pilot study evaluating the treatment of postparotidectomy sialoceles with botulinum toxin type A. Arch Otolaryngol Head Neck Surg 2000; 126:421-4.

9. von Lindern JJ, Niederhagen B, Appel T, et al. New pros- 
pects in the treatment of traumatic and postoperative parotid fistulas with type A botulinum toxin. Plast Reconstr Surg 2002;109:2443-5.

10. Marchese-Ragona R, Marioni G, Restivo DA, et al. The role of botulinum toxin in postparotidectomy fistula treatment. A technical note. Am J Otolaryngol 2006;27:221-4.

11. Capaccio P, Torretta S, Osio M, et al. Botulinum toxin therapy: a tempting tool in the management of salivary secretory disorders. Am J Otolaryngol 2008;29:333-8.

12. Taib BG, Williams SP, Sood S, et al. Treatment of sialorrhoea with repeated ultrasound-guided injections of botulinum toxin A into the parotid and submandibular glands. Br J Oral Maxillofac Surg 2019;57:442-8.

13. Hill SE, Mortimer NJ, Hitchcock B, et al. Parotid fistula complicating surgical excision of a basal cell carcinoma: successful treatment with botulinum toxin type A. Dermatol Surg 2007;33:1365-7.

14. Lim YC, Choi EC. Treatment of an acute salivary fistula after parotid surgery: botulinum toxin type A injection as primary treatment. Eur Arch Otorhinolaryngol 2008;265: 243-5.

15. Jung MS, Lee BH, Kim JH, et al. Treatment of botulinum toxin type A in parotid fistula after face lifting. Arch Aesthetic Plast Surg 2014;20:120-3.

16. Dessy LA, Mazzocchi M, Monarca C, et al. Combined transdermal scopolamine and botulinum toxin $\mathrm{A}$ to treat a parotid fistula after a face-lift in a patient with siliconomas. Int J Oral Maxillofac Surg 2007;36:949-52.

17. Kwon BY, Kim HS, Kim DH, et al. Use of botulinum toxin type A injection under ultrasonographic guidance for management of parotid sialocele: a case report and literature review. Arch Aesthetic Plast Surg 2017;23:146-8.

18. Bushara KO. Sialorrhea in amyotrophic lateral sclerosis: a hypothesis of a new treatment. Botulinum toxin A injections of the parotid glands. Med Hypotheses 1997;48:3379.

19. Marchese Ragona R, Blotta P, Pastore A, et al. Management of parotid sialocele with botulinum toxin. Laryngoscope 1999;109:1344-6.

20. Arnaud S, Batifol D, Goudot P, et al. Nonsurgical management of traumatic injuries of the parotid gland and duct using type a botulinum toxin. Plast Reconstr Surg 2006; 117:2426-30. 